\title{
Sistem Pakar Diagnosa Penyakit Kolesterol dan Asam Urat Menggunakan Metode Certainty Factor
}

\section{Charesterol and Uric Acid Disease Expert System Using Certainty Factor Method}

\author{
Patmawati Hasan ${ }^{* 1}$, Eka Wahyu Sholeha ${ }^{2}$, Yulius Nahak Tetik ${ }^{3}$, Kusrini ${ }^{4}$ \\ ${ }^{1}$ Universitas Amikom Yogyakarta; Jalan Ring Roud Utara, Telp: (0274) 884201 - 207 of \\ Universitas Amikom Yogyakarta \\ ${ }^{3}$ Magister Teknik Informatika, Amikom, Yogyakarta \\ e-mail: *1 patmawatihasan@gmaill.com, 2 eka.1005@ students.amikom.ac.id, \\ 3yuliusteti@gmail.com, ${ }^{4}$ kusrini@amikom.ac.id
}

\begin{abstract}
Abstrak
Saat ini Kolestrol dan Asam urat merupakan pernyakit yang tingkat kejadianya cukup tinggi. Berdasarkan ahli dari Clinical Research Support Unit (CRSU) Fakultas Kedokteran Universitas Indonesia, Dr. Nafrialdi, PhD menyatakan bahwa 35\% penduduk Indonesia memiliki kadar kolesterol lebih tinggi dari batas normal dan Menurut data WHO 2015, penderita asam urat di Indonesia terjadi pada usia dibawah 34 tahun sebesar $32 \%$ dan di atas 34 tahun sebesar 68\%. Namun ketidaktahuan masyrakat umum terhadap penyakit yang dialami di karenakan mahalnya biaya yang harus di keluarkan untuk mengetahui penyakit lebih dini tanpa harus berkonsultasi ke dokter. Untuk membantu mengatasi permasalahan tersebut penulis membuat program sistem pakar yang dapat mengidentifikasi penyakit kolestrol dan asam urat masyarakat umum. Namun kemampuan sistem dalam mendiagnosa suatu gejala tidak 100\% sama dengan diagnosa seorang dokter, masih banyak hal yang tidak pasti atau sehingga dapat menyebabkan kemungkinan kesalahan dalam diagnosa maka salah satu metode dalam perhitungan ketidakpastian adalah metode certainty factor $(C F)$. Metode Certainty Factor menyatakan kepercayaan dalam sebuah kejadian (fakta atau hipotesis) berdasarkan bukti atau penilaian pakar. Berdasarkan pengujian rekapitulasi sampel data dari 20 orang korespoden didapatkan 50\% berpotensi Kolestrol, 35\% berpotensi Asam Urat, dan 15\% Bukan kedua penyakit. Rekapitulasi Validasi Sistem melalui pakar memberikan keakuratan $80 \%$ terhadap sistem pakar tersebut.
\end{abstract}

Kata kunci-Sistem Pakar, Kolestrol dan Asam Urat, Certainty Factor

\begin{abstract}
Currently cholesterol and gout are a disease that has a high incidence rate. According to experts from the Clinical Research Support Unit (CRSU), Faculty of Medicine, University of Indonesia, Dr. Nafrialdi, PhD states that 35\% of Indonesia's population has higher than normal levels of cholesterol and According to WHO data in 2015, gout sufferers in Indonesia occur at the age of under 34 years by $32 \%$ and above 34 years at $68 \%$. But the general public's ignorance of the disease is experienced because of the high costs that must be spent to know the disease earlier without having to consult a doctor. To help overcome these problems the authors make an expert system program that can identify cholesterol and gout. But the system's ability to diagnose a symptom is not $100 \%$ the same as the diagnosis of a doctor, there are still many
\end{abstract}


things that are uncertain or so that it can cause possible errors in diagnosis, one method in calculating uncertainty is the certainty factor (CF) method. The Certainty Factor method expresses trust in an event (fact or hypothesis) based on evidence or expert judgment. Based on the recapitulation test of data samples from 20 respondents, $50 \%$ had the potential of cholesterol, 35\% had the potential for gout, and $15 \%$ were not both diseases. System Validation Recapitulation through experts provides $80 \%$ accuracy of the expert system.

Keywords - Expert System, Cholesterol and Uric acid, Certainty Factor

\section{PENDAHULUAN}

Di zaman sekarang ini, perkembangan teknologi sudah sangat cepat. Berbagai aktivitas manusia sudah dimudahkan dengan teknologi, semua dapat dilakukan bahkan apa yang tidak dibayangkan oleh manusia saat ini pun sudah mampu direalisasikan dengan teknologi. Sistem pakar atau expert system juga sudah banyak dikembangkan oleh sejumlah peneliti untuk berbagai bidang, namun yang banyak diimplementasikan adalah kesehatan. Baik manusia, hewan, maupun tumbuhan biasa didiagnosa penyakitnya melalui sistem pakar.

Pada manusia penyakit adalah penyebab gangguan kesehatan pada tubuh manusia yang menyerang sejumlah orang. Manusia seringkali telah mengetahui tubuhnya mengalami gangguan kesehatan, tetapi tidak tahu persis penyakit apa yang sedang menyerangnya serta bagaimana cara mengobatinya, sehingga untuk mengetahui dan mengatasi penyakit seorang ahli yang memahami masalah kesehatan (dokter, bidan, atau perawat).

Kolestrol dan Asam urat merupakan pernyakit yang tingkat kejadianya cukup luas dan dapat menyerang siapa saja tanpa memandang usia dan suku bangsa. Berdasarkan ahli dari Clinical Research Support Unit (CRSU) Fakultas Kedokteran Universitas Indonesia, Dr. Nafrialdi, PhD menyatakan bahwa 35\% penduduk Indonesia memiliki kadar kolesterol lebih tinggi dari batas normal dan Menurut data WHO 2015, penderita asam urat di Indonesia terjadi pada usia dibawah 34 tahun sebesar 32\% dan di atas 34 tahun sebesar 68\%. Kendala yang terjadi saat ini adalah ketidaktahuan masyrakat umum terhadap penyakit yang dialami di karenakan mahalnya biaya yang harus di keluarkan untuk mengetahui penyakit lebih dini tanpa harus berkonsultasi ke dokter. Maka perlu adanya sebuah sistem yang bisa memudahkan pasien dalam mendiagnosis penyakit yang dialami secara dini untuk mencegah penyakit tersebut ke tingkat yang lebih tinggi.

Sistem pakar pada saat ini sudah banyak digunakan manusia, seperti memudahkan masyarakat tanpa harus berkonsultasi dengan dokter atau pakar, bisa mengetahui gejala penyakit lebih dini, atau juga bisa sebagai data pendukung saat berkonsultasi dengan dokter atau pakar terkait sesuai dengan hasil dari sistem pakar tersebut. Sistem pakar dirancang agar dapat menyelesaikan suatu permasalahan tertentu dengan meniru kerja para pakar atau ahli. Pengalihan keahlian dari para ahli ke komputer untuk kemudian dialihkan lagi ke orang lain yang bukan ahli merupakan tujuan utama dari sistem pakar [1].

Untuk membantu mengatasi permasalahan tersebut penulis membuat program sistem pakar yang dapat digunakan untuk mengidentifikasi masalah-masalah penyakit kolestrol dan asam urat yang di alami masyarakat umum. Kemampuan sistem dalam mendiagnosa suatu gejala tidak $100 \%$ sama dengan diagnosa seorang dokter, masih banyak hal yang tidak pasti atau tidak konsisten sehingga dapat menyebabkan kemungkinan kesalahan dalam diagnosa. Ketidak konsistenan ini dapat menyebabkan keraguan hasil diagnosa sistem dan dapat menimbulkan sebuah pertanyaan tentang besarnya prosentase kepastian hasil diagnosa tersebut. Perhitungan ketidakpastian diperlukan dalam sistem pakar untuk dapat meyakinkan pasien (pengguna sistem) akan hasil diagnosa yang dihasilkan sehingga sistem pakar yang dibuat benar-benar seperti layaknya diagnosa seorang dokter sebagai pakar dalam bidang tersebut. Oleh karena

\section{Jurnal Ilmiah SISFOTENIKA}


banyak hal yang tidak pasti atau tidak konsisten maka di perlukan perhitungan kepastian yaitu metode Certainty untuk mendiagnosa penyakit Kolestrol dan Asam urat.

Perhitungan ketidakpastian dalam sistem pakar dapat dilakukan dengan beberapa metode ketidakpastian. Salah satunya adalah dengan menggunakan metode Certainty Factor. Metode ini merupakan perhitungan tingkat kepastian terhadap kesimpulan yang diperoleh dan dihitung berdasarkan nilai probabilitas penyakit karena adanya evident gejala. Diharapkan dengan penggunaan metode Certainty Factor dapat mengurangi ketidakpastian sehingga dapat menghasilkan diagnosis yang valid [2].

Dari hasil penelitian dan pengujian yang dilakukan sebelumnya, implementasi metode Certainty Factor dalam sistem pakar dapat membantu dalam mendiagnosis jenis penyakit dermatitis berdasarkan gejala yang dirasakan [3]. Pada penelitian yang dilakukan oleh Sthepanie, menggunakan metode Certainty Factor dalam pengujiannya dengan melibatkan dua orang dokter pada sistem pakar pendeteksi resiko osteoporosis dan osteoarthtritis [4]. Kemudian oleh Rofiqoh, membuat sistem pakar diet sehat menggunakan metode Certainty Factor namun kurang menjelaskan secara detil penggunaan metode Certainty Factor dalam penelitian tersebut[5]. Penelitian selanjutnya menggunakan metode certainty factor ketika menghadapi suatu masalah yang jawabannya tidak pasti. Ketidakpastian ini bisa merupakan probabilitas. Metode ini pernah dilakukan Elizabeth untuk penanganan penyakit insomnia dari asisten akupunturis dikarenakan pakar akupunturis tidak selalu berada di klinik [6]. Keunggulan dari sistem yang dibangun bersifat dinamis sehingga data basis pengetahuan dapat di tambahkan atau dirubah oleh pakar. Dari sisi pengguna juga mendapatkan kemudahan dalam mengakses sistem tersebut dengan langsung menginputkan gejala yang dirasakan dan mendapatkan hasil diagnosa penyakit kolestrol atau asam urat.

Pada pembahasan dibawah ini, penerapan metode Certainty Factor melalui sistem pakar untuk mendiagnosis penyakit kolestrol dan asam urat agar meyakinkan pasien (pengguna sistem) akan hasil diagnosa yang dihasilkan sama dengan hasil dokter sama sehingga sistem pakar yang dibuat benar-benar seperti layaknya diagnosa seorang dokter sebagai pakar dalam bidang tersebut. Metode Certainty Factor atau Faktor kepastian menyatakan kepercayaan dalam sebuah kejadian (fakta atau hipotesis) berdasarkan bukti atau penilaian pakar [7]. Alasan penggunaan metode Certainty Factor karena dapat memberikan hasil yang akurat yang didapatkan dari perhitungan berdasarkan bobot gejala yang dipilih pengguna, mampu memberikan jawaban pada permasalahan yang tidak pasti kebenarannya seperti masalah diagnosa penyakit, dan dengan metode ini pakar menggambarkan keyakinan seorang pakar dengan memberikan bobot keyakinan sesuai dengan pengetahuan pakar terkait. Aplikasi akan dibangun dengan berbasis $W E B$ agar mudah di jangkau masyarakat umum.

\section{METODE PENELITIAN}

Metode Penelitian memaparkan alur analisis, gambaran umum sistem, DFD diagram konteks, relasi antar tabel, basis pengetahuan, dan pembahasan metode Certainty Factor [8].

\subsection{Alur Analisis}

Alur analisis dari penelitian memaparkan tentang bagaimana proses analisis masalah sampai sistem yang direncanakan berjalan dengan baik. Berikut adalah proses- prosesnya.

1. Pendefinisian permasalahan dari aplikasi yang ingin dibuat untuk menambah pemahaman mengenai hal tersebut. Dari pendefinisian ini didapat beberapa rumusan masalah.

2. Pengumpulan data yang berhubungan dengan perancangan dan pembuatan sistem : melalui observasi, wawancara, dan studi literatur.

3. Pemahaman terhadap proses-proses yang terjadi, sehingga dapat dilakukan suatu pemodelan data. 
4. Pembuatan perangkat lunak. Pem- buatan perangkat lunak dibagi menjadi dua bagian yaitu pembuatan server database dan web.

5. Pengujian terhadap perangkat lunak yang telah dibuat dengan cara me- masukkan beberapa contoh data.

6. Pengambilan kesimpulan untuk me- ngetahui hasil dari penelitian dan dapat memberikan saran atas pengembangan aplikasi selanjutnya.

\subsection{Gambaran Umum Sistem}

Sistem pakar yang akan dibuat menggunakan sistem pakar berbasis web dan akan difungsikan bagi pengguna internet yang memerlukan informasi tentang cara mendiagnosa penyakit Kolestrol dan Asam Urat. Untuk membuat aplikasi ini, diperlukan beberapa aplikasi antara lain: PHP editor, CSS, HTML untuk mengetikkan syntax, Sublime Text 3 untuk pendesain web, tempat peyimpanan data akan memanfaatkan database MySQL, dan XAMPP sebagai localhostnya.

\subsection{DFD Diagram Konteks}

Konteks diagram menggambarkan tentang gambaran secara umum bagaimana aliran data yang terjadi dalam sistem, dapat dilihat pada Gambar 1.

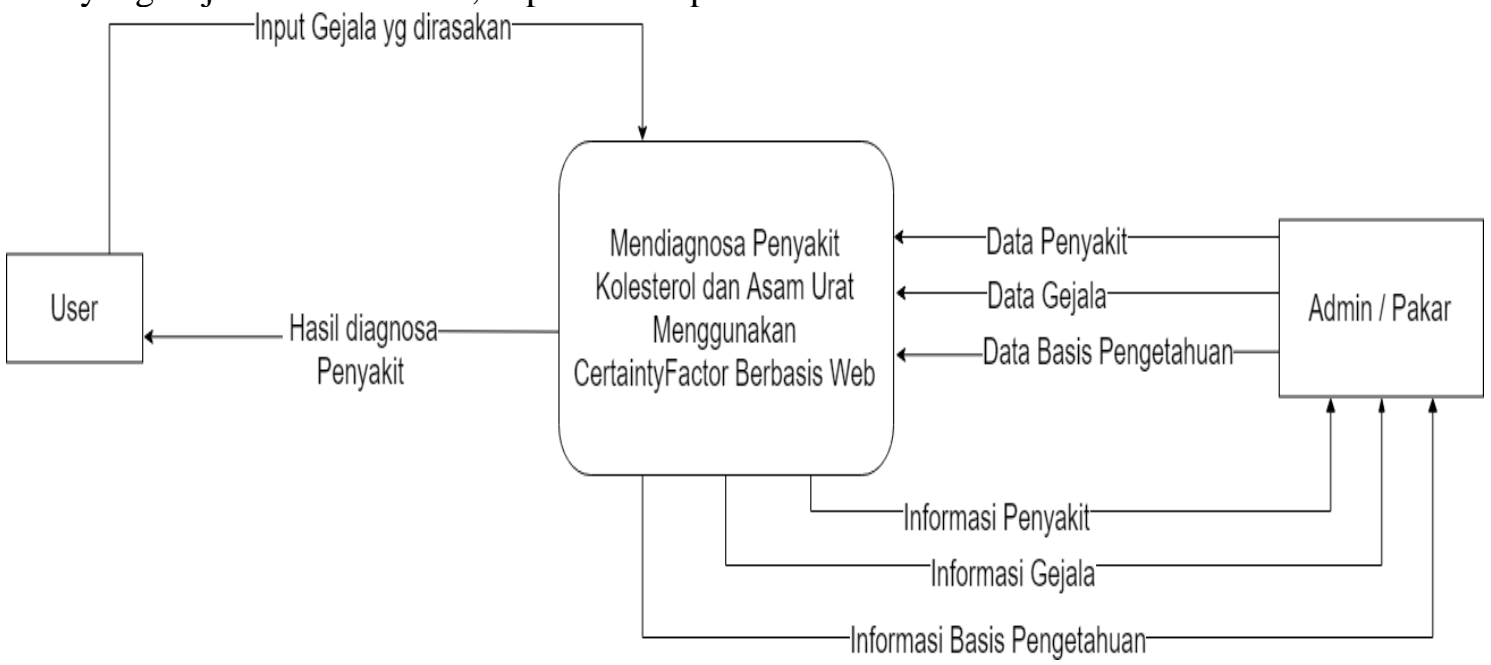

Gambar 1. Diagram konteks

\subsection{Relasi Antar Tabel}

Relasi antar tabel merupakan hubungan antar tabel dalam database Sistem Pakar Diagnosa Penyakit Kolesterol dan Asam Urat, dapat dilihat pada Gambar2. 


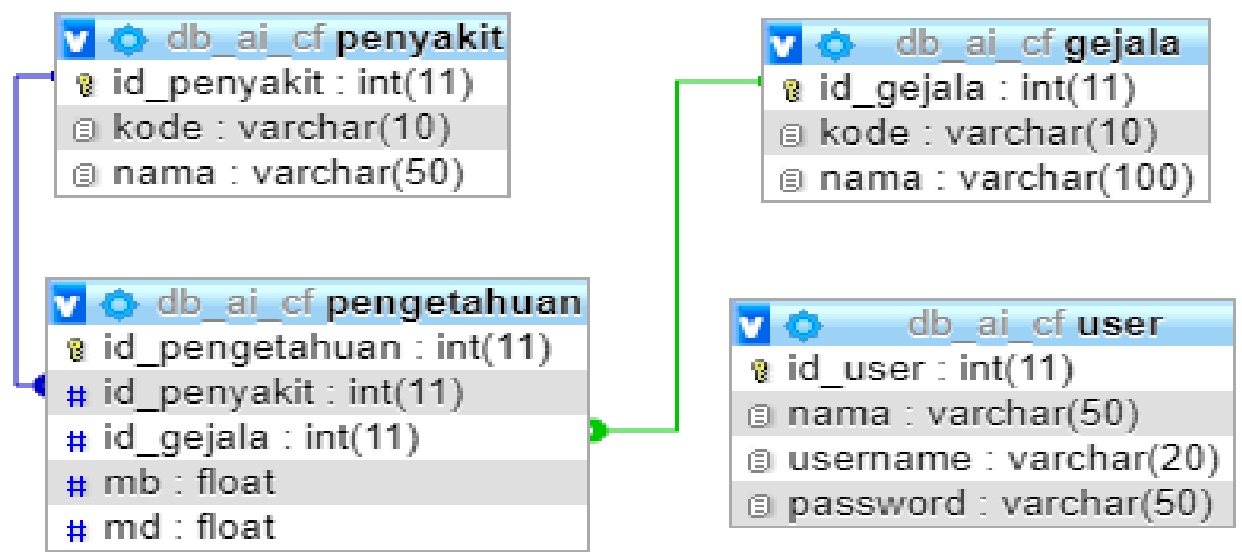

Gambar 2. Relasi antar tabel

Relasi antar tabel di atas menggambarkan suatu media penyimpanan yang digunakan untuk menyimpan data penunjang sebagai inputan sistem dan kemudian diolah menjadi data output sistem.

\subsection{Basis Pengetahuan}

Keberhasilan suatu aplikasi sistem pakar terletak pada pengetahuan dan bagaimana mengolah pengetahuan tersebut agar dapat ditarik suatu kesimpulan. Tabel jenis penyakit dan gejala ini digunakan sebagai pola pencocokan informasi yang dimasukan oleh pemakai dan basis pengetahuan, dapat dilihat pada Tabel 1 .

Tabel 1. Basis pengetahuan (Aturan)

\begin{tabular}{|c|c|c|c|c|}
\hline \multicolumn{5}{|c|}{ Basis Pengetahuan (Aturan) } \\
\hline $\begin{array}{c}\text { Nama } \\
\text { Penyakit }\end{array}$ & $\begin{array}{l}\text { Kode } \\
\text { Gejala }\end{array}$ & Nama Gejala & MB & MD \\
\hline \multirow{5}{*}{ KOLESTROL } & G01 & Rasa sakit pegal di kepala & 0.8 & 0.2 \\
\hline & G03 & Mudah capek & 0.6 & 0.2 \\
\hline & G04 & Gampang mengantuk & 0.6 & 0 \\
\hline & G06 & Pegal sampai ke pundak & 1 & 0 \\
\hline & G08 & Kaki bengkak & 0.8 & 0 \\
\hline ASAM & G02 & Nyeri sendi saat bangun tidur & 0.6 & 0.2 \\
\hline \multirow[t]{3}{*}{ URAT } & G05 & Rasa panas pada sendi & 0.8 & 0 \\
\hline & G07 & Jempol Kaki Terasa Nyeri & 0.8 & 0.2 \\
\hline & G09 & Persendian susah digerakkan & 1 & 0 \\
\hline
\end{tabular}

Keterangan gejala dan penyakit:

Gejala yang diberikan berdasarkan informasi dari pakar:

[G01] Rasa sakit pegal di kepala

[G02] Nyeri sendi saat bangun tidur

[G03] Mudah capek

[G04] Gampang mengantuk

[G05] Rasa panas pada sendi

[G06] Pegal sampai ke pundak

[G07] Jempol Kaki Terasa Nyeri

[G08] Kaki bengkak

[G09] Persendian susah digerakkan 
Peyakit:

[K01] Kolestrol

[A02] Asam Urat

\subsection{Pembahasan Metode Certainty Factor}

Faktor kepastian (Certainty Faktor) menyatakan kepercayaan dalam sebuah kejadian (fakta atau hipotesis) berdasarkan bukti atau penilaian pakar [7]. Berikut notasi faktor kepastian:

$\mathrm{CF}(\mathrm{h}, \mathrm{e})=\mathrm{MB}(\mathrm{h}, \mathrm{e})-\mathrm{MD}(\mathrm{h}, \mathrm{e})$

Keterangan:

$\mathrm{CF}(\mathrm{h}, \mathrm{e}) \quad$ : certainty factor dari hipotesis h yang dipengaruhi oleh gejala (evidence) e. Besarnya CF berkisar antara -1 sampai dengan 1.Nilai -1 menunjukkan ketidakpercayaan mutlak sedangkan nilai 1 menunjukkan kerpercayaan mutlak.

$\mathrm{MB}(\mathrm{h}, \mathrm{e}) \quad$ : ukuran kenaikan kepercayaan (measure of increased belief) terhadap hipotesis h yang dipengaruhi oleh gejala e.

$\mathrm{MD}(\mathrm{h}, \mathrm{e}) \quad$ : ukuran kenaikan ketidakpercayaan (measure of increased disbelief) terhadap hipotesis h yang dipengaruhi oleh gejala e.

h $\quad$ : Hipotesa (antara 0 dan 1)

E : Peristiwa / fakta (evidence)

Dalam satu kasus akan terdapat lebih dari satu ukuran kenaikan kepercayaan sesuai dengan banyak gejala yang dimiliki oleh hipotesa, sehingga rumus MB dan MD sebagai berikut:

$$
\begin{gathered}
M B\left[h, e_{1} \Delta e_{2}\right]=\left\{\begin{array}{cr}
0 & M D\left[h, e_{1} \Delta e_{2}\right]=1 \\
M B\left[h, e_{1}\right]+M B\left[h, e_{2}\right] .\left(1-M B\left[h, e_{1}\right]\right) & \text { lainnya }
\end{array}\right. \\
M D\left[h, e_{1} \Delta e_{2}\right]=\left\{\begin{array}{lr}
0 & M B\left[h, e_{1} \Delta e_{2}\right]=1 \\
M D\left[h, e_{1}\right]+M D\left[h, e_{2}\right] .\left(1-M D\left[h, e_{1}\right]\right) & \text { lainnya }
\end{array}\right.
\end{gathered}
$$

Misalkan pasien menginput gejala yang dipilih adalah [G01] Rasa sakit pegal dikepala dengan nilai kepercayaan 0.8, [G06] Pegal sampai kepundak dengan nilai 1.00, [G08] kaki bengkak dengan nilai 0.8, [G02] Nyeri sendi saat bangun tidur pilihan jawaban yakin dengan nilai 0.6. Pada contoh kasus perlu diketahui bahwa pasien menginputkan gejala-gejala yang terdapat pada penyakit Kolestrol dan Asam Urat. Sehinga pada perhitungan menggunakan metode Certainty Factor akan mendapatkan hasil diagnosa berdasarkan hasil persentase paling tinggi dari kedua penyakit tersebut. Berikut adalah gejala tabel berdasarkan nilai MB dan MD, dapat dilihat pada Tabel 2.

Tabel 2. Contoh gejala yang dipilih

\begin{tabular}{clcc}
\hline $\begin{array}{c}\text { Kode } \\
\text { Gejala }\end{array}$ & \multicolumn{1}{c}{$\begin{array}{c}\text { Gejala yang } \\
\text { Dipilih }\end{array}$} & MB & MD \\
\hline G1 & Rasa sakit pegal di kepala & 0.8 & 0.2 \\
\hline G6 & Pegal sampai ke pundak & 1 & 0 \\
\hline G8 & Kaki bengkak & 0.8 & 0 \\
\hline G2 & Nyeri sendi saat bangun tidur & 0.6 & 0.2 \\
\hline
\end{tabular}


Perhitungan dengan metode Certainty Factor adalah sebagai berikut. Berikut perhitungan pada persamaan $(1,2,3)$ :

1. Penyakit 1 : Kolestrol

Gejala $1 \quad$ : [G01]Rasa sakit pegal dikepala

MB Lama : : 0

MD Lama $\quad: 0$

MB Baru $\quad: 0.8$

MD Baru $\quad: 0.2$

MB Sementara $: 0.8$

MD Sementara $: 0.2$

Gejala $2 \quad$ : [G06]Pegal sampai kepundak

MB Lama $\quad: 0.8$

MD Lama $\quad: 0.2$

MB Baru $\quad: 1$

MD Baru : : 0

MB Sementara : MB Lama + (MB Baru * (1 - MB Lama))

$: 0.8+(1 *(1-0.8))$

$: 1$

MD Sementara : MD Lama + (MD Baru * (1 - MD Lama $))$

$: 0.2+(0 *(1-0.2))$

$: 0.2$

Gejala $3 \quad$ : [G08]Kaki bengkak

MB Lama $\quad: 1$

MD Lama $\quad: 0.2$

MB Baru $\quad: 0.8$

MD Baru $\quad: 0$

MB Sementara : MB Lama + (MB Baru * (1 - MB Lama)

$: 1+(0.8 *(1-1))$

$: 1$

MD Sementara : MD Lama + (MD Baru * (1 - MB Lama)

$: 0.2+(0 *(1-0))$

$: 0.2$

CF : MB Sementara - MD Sementara

$: 1-0.2$

$: 0.8$

CF $: 0.8 * 100 \%$

: $80 \%$ [Kolestrol]

2. Penyakit 2 : Asam Urat
Gejala 4
: [G02] Nyeri sendi saat bangun tidur
MB Lama
$: 0$
MD Lama
$: 0$
MB Baru
$: 0.6$
MD Baru
$: 0.2$
MB Sementara : 0.6 


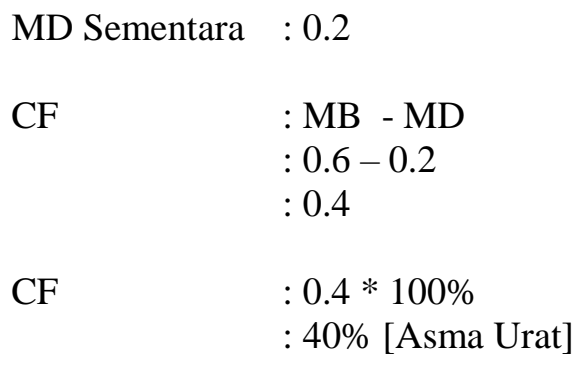

Dari hasil perhitugan menggunakan metode Certainty Factor pada persamaan $(1,2,3)$ dengan menginputkan 4 gejala yaitu [G10] Rasa sakit pegal dikepala dengan nilai kepercayaan 0.8, [G06] Pegal sampai kepundak dengan nilai 1.00, [G08] kaki bengkak dengan nilai 0.8, [G02] Nyeri sendi saat bangun tidur pilihan jawaban yakin dengan nilai 0.6 mendapatkan hasil diagnosa gejala penyakit kolestrol sebesar $80 \%$ dan asam urat sebesar $40 \%$. Namun hanya persentase yang lebih tinggi yang akan dijadikan keputusan akhir sebagai hasil diagnosa. Keputusan akhir yaitu penyakit Kolestrol yang memiliki persentase tertinggi sebagai hasil diagnosa.

\section{HASIL DAN PEMBAHASAN}

Hasil dan pembahasan memaparkan mengenai tampilan dan hasil uji coba perangkat lunak pembangunan sistem pakar mendiagnosa penyakit Kolestrol dan Asam urat berbasis web dengan menggunakan metode Certainty Faktor.

\subsection{Halaman Login Admin}

Halaman login admin merupakan halaman pembuka pada admin untuk dapat membuka sistem pakar, dapat dilihat pada Gambar 3.

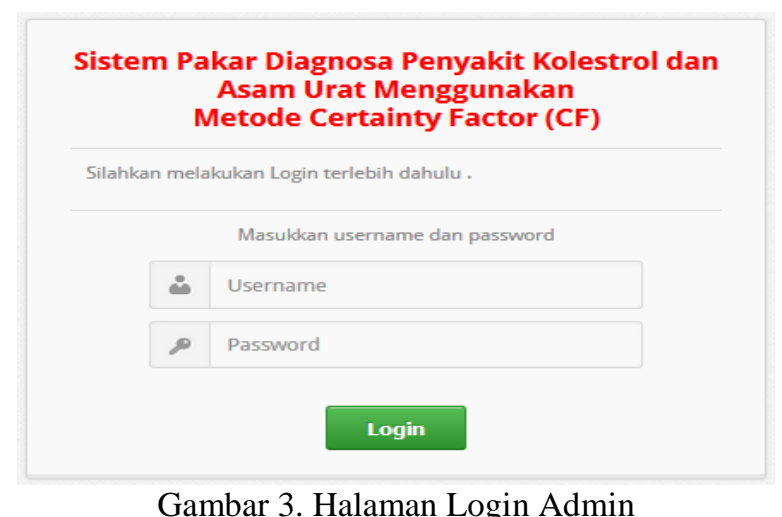

\subsection{Halaman Menu Admin}

Halaman Menu admin merupakan halaman pembuka dari sistem pakar ketika berhasil melakukan Login, dapat dilihat pada Gambar 4. 


\section{Menu Utama Sistem Pakar Diagnosa Penyakit Kolestrol dan \\ - Halaman Depan Asam Urat}

, Data Penyakit

- Data Gejala

, Basis Pengetahuan

- Ubah Password

, Sign Out

Sistem Pakar Metode Certainty Factor (CF).

Sistem ini dibuat dengan tujuan untuk membantu user dalam mendiagnosa jenis penyakit berdasarkan gejala yang dialami.

Gambar 4. Halaman Menu Admin

Pada Gambar 4 terdapat menu data penyakit, data gejala, basis pengetahuan, ubah password dan sign out pada halaman.

\subsection{Halaman Menu Data Penyakit}

Halaman menu data penyakit merupakan halaman data penyakit Kolestrol dan Asam Urat, dapat dilihat pada Gambar 5.

\section{Menu Utama Data Penyakit}

- Halaman Depan
, Data Penyakit
- Bata Gejala
, Ubah Password
- Sign Out

\begin{tabular}{|l|l|l|l|l|l|}
\hline NO & \multicolumn{2}{|c|}{ KODE } & & + Tambah data penyakit \\
\hline 1 & A02 & Asam Urat & NAMA PENYAKIT & \\
\hline 2 & K01 & Kolestrol & 6 & 䈏 \\
\hline
\end{tabular}

Gambar 5. Halaman Menu Data Penyakit

\subsection{Halaman Menu Data Gejala}

Halaman menu data gejala merupakan daftar gejala dari penyakit Kolestrol dan Asam urat, dapat dilihat pada Gambar 6.

\section{Data Gejala}

\begin{tabular}{|c|c|c|c|c|}
\hline \multirow[b]{2}{*}{ NO } & \multirow[b]{2}{*}{ KODE } & \multirow[b]{2}{*}{ NAMA GEJALA } & \multicolumn{2}{|c|}{ + Tambah data gejala } \\
\hline & & & & \\
\hline 1 & G01 & Rasa sakit pegal dikepala & $\mathbb{E}$ & 笛 \\
\hline 2 & G02 & Nyeri sendi saat bangun tidur & $\mathbb{E}$ & 贯 \\
\hline 3 & G03 & Mudah capek & $\mathbb{E}$ & 笛 \\
\hline 4 & G04 & Gampang mengantuk & $\mathbb{E}$ & 笛 \\
\hline 5 & G05 & Rasa panas pada sendi & 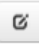 & 㽞 \\
\hline 6 & G06 & Pegal sampai ke pundak & $\mathbb{E}$ & 笛 \\
\hline 7 & G07 & Jempol Kaki Terasa Nyeri & 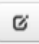 & 畕 \\
\hline 8 & G08 & Kaki bengkak & $\mathbb{E}$ & 曾 \\
\hline 9 & G09 & Persendian susah digerakkan & $\mathbb{E}$ & 笛 \\
\hline
\end{tabular}

Gambar 6. Halaman Menu Data Gejala 
Sistem Pakar Diagnosa Penyakit Kolesterol dan Asam Urat ...

\subsection{Halaman Menu Data Basis Pengetahuan}

Halaman menu data basis pengetahuan merupakan halaman untuk memasukkan tingkat kepercayaan dan ketidakpercayaan dari sebuah gejala berdasarkan pengetahuan pakar, dapat dilihat pada Gambar 7.

\section{Data Basis Pengetahuan}

\begin{tabular}{|c|c|c|c|c|c|c|}
\hline \multirow[b]{2}{*}{ NO } & \multirow[b]{2}{*}{ NAMA PENYAKIT } & \multirow[b]{2}{*}{ NAMA GEJALA } & \multicolumn{4}{|c|}{ Tambah data basis pengetahuan } \\
\hline & & & MB & MD & & \\
\hline 1 & Asam Urat & Nyeri sendi saat bangun tidur & 0.6 & 0.2 & $\mathbb{Z}$ & 苗 \\
\hline 2 & Asam Urat & Rasa panas pada sendi & 0.8 & 0 & $\mathbb{G}$ & 苗 \\
\hline 3 & Asam Urat & Jempol Kaki Terasa Nyeri & 0.8 & 0.2 & $\mathbb{C}$ & 畐 \\
\hline 4 & Asam Urat & Persendian susah digerakkan & 1 & 0 & $\mathbb{E}$ & 亶 \\
\hline 5 & Kolestrol & Rasa sakit pegal dikepala & 0.8 & 0.2 & $\mathbb{C}$ & 笛 \\
\hline 6 & Kolestrol & Mudah capek & 0.6 & 0.2 & $\mathbb{G}$ & 苗 \\
\hline 7 & Kolestrol & Gampang mengantuk & 0.6 & 0 & $\mathbb{G}$ & 笛 \\
\hline 8 & Kolestrol & Pegal sampai ke pundak & 1 & 0 & $\mathbb{G}$ & 笛 \\
\hline 9 & Kolestrol & Kaki bengkak & 0.8 & 0 & $\mathbb{C}$ & 笛 \\
\hline
\end{tabular}

Gambar 7. Halaman Menu Data Basis Pengetahuan

\subsection{Halaman Gejala User}

Halaman gejala user merupakan halaman yang langsung dikunjungi user tanpa melakukan login terlebih dahulu, dapat dilihat pada Gambar 8.

\section{Sistem Pakar Diagnosa Penyakit Kolestrol dan Asam Urat}

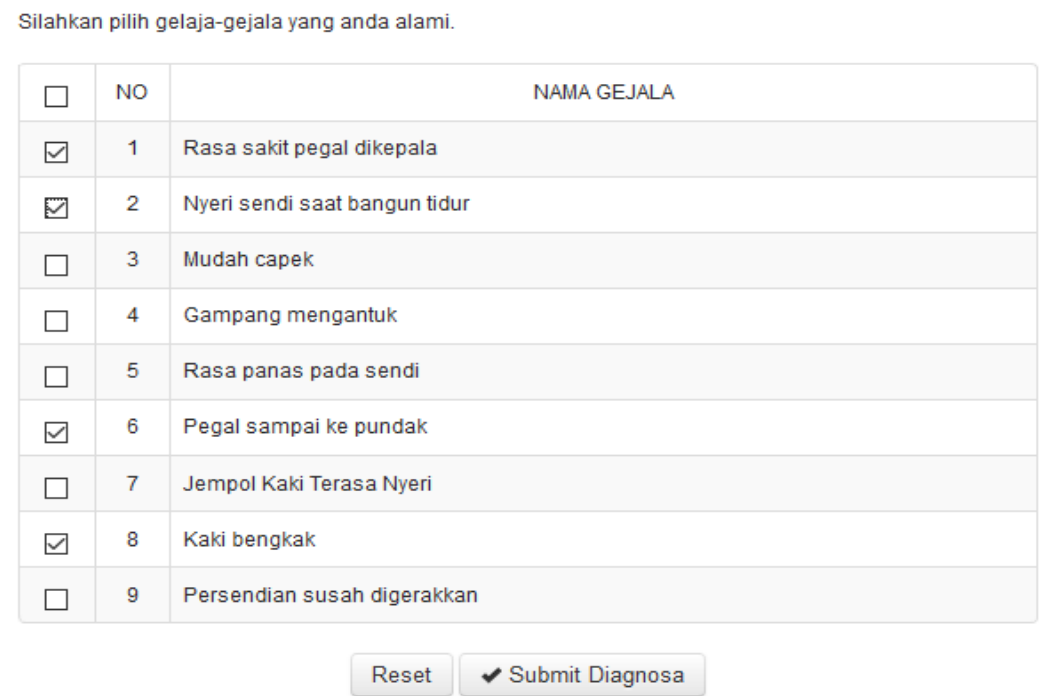

Gambar 8. Halaman Gejala User 


\subsection{Hasil Diagnosa User}

Halaman hasil diagnosa user merupakan hasil akhir dari pengujian gejala yang diinputkan user, dapat dilihat pada Gambar 9.

\section{Hasil Diagnosa}

\begin{tabular}{l} 
Gejala-gejala yang anda alami : \\
\begin{tabular}{|l|l|l|}
\hline 1 & G01 & Rasa sakit pegal dikepala \\
\hline 2 & G02 & Nyeri sendi saat bangun tidur \\
\hline 3 & G06 & Pegal sampai ke pundak \\
\hline 4 & G08 & Kaki bengkak \\
\hline
\end{tabular} \\
\hline
\end{tabular}

\section{Data Analisa}

\begin{tabular}{|c|c|c|c|c|}
\hline NO & KODE & NAMA PENYAKIT & $\mathrm{CF}$ & RANK \\
\hline 1 & K01 & Kolestrol & $80 \%$ & 1 \\
\hline 2 & $\mathrm{~A} 02$ & Asam Urat & $40 \%$ & 2 \\
\hline \multicolumn{2}{|c|}{ Nama Penyakit } & \multicolumn{3}{|l|}{ KOLESTROL } \\
\hline
\end{tabular}

$$
\begin{array}{l|l}
\text { Pilih Gejala/ Kembali Cetak } \\
\hline
\end{array}
$$

Gambar 9. Hasil Diagnosa User

\subsection{Pengujian Fungsionalitas}

Dari hasil perhitungan manual pada persamaan $(1,2,3)$ dan gambar 9 hasil diagnosa user, dapat disimpulkan bahwa pasien tersebut berpotensi penyakit Kolestrol karena nilai Certainty Factor Kolestrol lebih besar dari nilai Certainty Factor Asam Urat.

1. Rekapitulasi Sampel Data

Berikut rekapitulasi sampel data yang melibatkan 20 orang koresponden yang juga menguji aplikasi dengan memasukkan gejala yang dirasakan pada Tabel 3.

Tabel 3. Rekapitulasi Sampel Data

\begin{tabular}{cccc}
\hline No & Hasil Diagnosa & Jumlah Orang & Persentase \\
\hline 1 & Kolestrol & 10 & $50 \%$ \\
\hline 2 & Asam Urat & 7 & $35 \%$ \\
\hline 3 & Bukan Kedua Penyakit & 3 & $15 \%$ \\
\hline
\end{tabular}

2. Rekapitulasi Validasi Sistem Melalui Pakar

Setelah sample data didapat, sample tersebut di konsultasikan lagi dengan pakar atau dokter untuk diuji keakuratannya. Pada penelitian ini melibatkan 1 orang dokter yaitu Dr. Nurmin Arifin yang memberikan data gejala beserta nilai bobot menguji sistem ini memberikan keakuratan $80 \%$ terhadap sistem tersebut.

\section{KESIMPULAN}


Setelah menguraikan secara keseluruhan Sistem Pakar Dignosis Penyakit Kolestror dan Asam urat Mennggunakan Metode Certainty Factor dapat ditarik kesimpulan sebagai berikut:

1. Sistem pakar untuk mendiagnosa penyakit Kolestrol dan Asam urat menggunakan metode Certainty Factor memiliki keunggulan yang berbeda dari penelitian sebelumnya dimana sistem yang dibangun bersifat dinamis sehingga data basis pengetahuan dapat di tambahkan atau dirubah oleh pakar. Dari sisi pengguna juga mendapatkan kemudahan dalam mengakses sistem tersebut dengan langsung menginputkan gejala yang dirasakan dan mendapatkan hasil diagnosa penyakit kolestrol atau asam urat.

2. Berdasarkan hasil rekapitulasi sampel data dari 20 orang korespoden didapatkan $50 \%$ berpotensi Kolestrol, 35\% berpotensi Asam Urat, dan 15\% Bukan kedua penyakit. Rekapitulasi Validasi Sistem melalui pakar memberikan keakuratan $80 \%$ terhadap sistem tersebut.

\section{SARAN}

Diharapkan nantinya dapat mencakup banyak gejala yang lebih spesifikasi dan sistem juga dapat memberikan solusi pada tiap penyakit. Sehingga sistem tidak hanya mendiagnosis secara dini penyakit Kolestrol dan Asam Urat saja, namun dapat memberikan solusi dari masing-masing penyakit. Kemudian, diharapkan sistem dapat dikembangkan tidak hanya melalui website tapi bisa juga melalui smartphone atau tablet agar mempermudah pengguna untuk mengakses sistem tersebut.

\section{DAFTAR PUSTAKA}

[1] Heriyanto, P., Indah, F, A., Dedy, C, 2017,. Sistem Pakar Berbasis WEB Diagnosa Penyakit THT (Telinga, Hidung, Tenggorokan) Menggunakan Metode Certainty Factor, Prosiding SAKTI (Seminar Ilmu Komputer dan Teknologi Informasi), Vol 2, No.2.

[2] Fahruddin Ghozali, M., \& Eviyanti, A, 2016, Sistem Pakar Diagnosis Dini Penyakit Leukemia Dengan Metode Certainty Factor, Journal Kinetik, 1(3), 135-146.

[3] Findawati, Y., \& Afrina, A. I, 2018, Expert System Diagnose Disease Dermatitis Using Web Based Certainty Factor, IOP Conference Series: Materials Science and Engineering, Vol 403.

[4] Halim, S., \& Hansun, S. (2016). Penerapan Metode Certainty Factor dalam Sistem Pakar Pendeteksi Resiko Osteoporosis dan Osteoarthritis. Jurnal ULTIMA Computing, 7(2), 59-69.

[5] Rofiqoh, D, 2014, Sistem Pakar Diet Sehat Bertipe Genotipe Menggunakan Metode Certainty Factor, Journal SISFOTENIKA, Vol 4, No.2, hal 163-174.

[6] Elizabeth, P., Retantyo, W., 2018, An Expert System Using Certainty Factor for Determining Insomnia Acupoint, IJCCS (Indonesian Journal of Computing and Cybernetics Systems), Vol.12, No.2, hal 119-128.

[7] Kusumadewi, Sri., 2003, Artificial Intelligence (Teknik dan Aplikasinya), Yogyakarta : Graha Ilmu.

[8] Gede, I, F, J., Ketut, I, A, P., 2016, Sistem Pakar Untuk Mendiagnosa Penyakittelinga Hidung Dan Tenggorokan (THT) dengan Metode Certainty Factor Berbasis WEB, EJournal SPEKTRUM, Vol 3, No.1, hal 14-20. 